\title{
The Development and Confirmatory Factor Analysis of a Scale for the Measurement of Gifted Students Attitude towards Mathematics
}

\author{
Alaba Adeyemi Adediwura \\ Department of Educational Foundations and Counselling \\ Obafemi Awolowo University, Ile-ile, Nigeria \\ Tel: +234-803-381-8747 \\ E-mail: yemtoy20002000@yahoo.com
}

Received: February 25, 2011 Accepted: March 15, $2011 \quad$ doi:10.5430/wje.v1n1p52

\begin{abstract}
The present study was aimed at developing an attitude scale and then use it to reveal the attitude of mathematical gifted students' attitude towards mathematics. In the first phase of the study, an attitude-scale (AS) towards mathematics were designed using the psychometric approach. The AS was composed of seventeen items aimed to measure four factors of attitude: confidence, perceived value of mathematics, interest and commitment, and negative feelings towards mathematics. The AS was piloted with 50 students of a junior secondary III (JS3). Alpha of the AS was found to be 0.93 , and the construct validity with the four-factor structure was confirmed with AGFI = 0.99.

In the second phase of the study, the AS were administered on three groups of JS3 students: the mathematically gifted group (MG), the average group (AV) and the underachievers' group (U), as identified in the study. Group sizes for the three groups were 68, 195 and 37 respectively. It was found that MG performed significantly better than both U and AV in all the three factors of mathematical abilities. MG also showed significantly better attitudes than AV in 'confidence', 'value', 'interest' and 'negative feelings', and significantly better attitudes than U in 'interest'.
\end{abstract}

Keywords: Factor Analysis, Attitude towards mathematics, Mathematical Giftedness

\section{Introduction}

The IQ definition simply defines "giftedness" as top performance in standardized intelligence tests. The IQ definition is perhaps the most well known definition, and has its origin in the 1920s when the famous American psychologist Lewis Terman identified 1528 children with Stanford-Binet IQ scores above 135, the upper one percent, and did some historical longitudinal studies about gifted children later. Following from this psychometric tradition, many clinical and educational psychologists describe a child as "gifted” if his/her IQ score is found to be above a certain number, usually 130 or 135 . According to the psychometric IQ definition, a point is set on the IQ scale, and persons scoring above that point are classified as "gifted". Usually 130 is the cut-off point, equivalent to the 97.9th percentile on a standardized intelligence test with a standard deviation of $\sigma=15$.

Based on Marland (1972), the U.S. Office of Education defined gifted and talented as follows:

"Gifted and talented children are those identified by professionally qualified persons who by virtue of outstanding abilities are capable of high performance. These are children who require differentiated educational programs and services beyond those normally provided by the regular school program in order to realize their contribution to self and society.

"Children capable of high performance include those with demonstrated achievement and/or potential in any of the following areas:

1. General intellectual ability

2. Specific academic aptitude

3. Creative or productive thinking

4. Leadership ability

5. Visual and performing arts

6. Psychomotor ability”

(Davis \& Rimm, 1998; p. 18) 
Ridge and Renzulli (1981) argued that the above Federal definition of gifted and talented does not include nonintellective (motivational) factors. Renzulli (1986) thus proposed his three-ring model of giftedness. The three-ring model of giftedness defines giftedness as the interaction of task commitment, creativity, and above average ability. This highlights the importance of affective elements, such as interest and persistence, in the development of giftedness. The present author also regards affective elements as highly important, and so has included attitude in the present study of mathematical giftedness.

According to Davis and Rimm (1998), there is no single universally-accepted definition of "gifted," or "giftedness". Consequently, there is no one universally accepted definition of mathematical giftedness. The achievement test definition simply defines 'mathematical giftedness' as top performance in standardized mathematical achievement tests or ability tests. This might set a fixed proportion of the school children as gifted. The percentage figure may be a generous one from $15 \%$ to $20 \%$, or a more restrictive one, from $1 \%$ to $5 \%$. Researchers have provided another well-known example of using standardized mathematical achievement tests to define mathematical giftedness. For more than twenty years, they investigated extreme mathematical talent, as defined by very high SAT scores in mathematics. Some controversial findings, such as many more males than females scored above 700 on the SAT-M examination have been obtained (Benbow, 1991; Stanley, Keating \& Fox, 1974).

Some have proposed using achievement tests, together with IQ scores as providing a composite criterion for identifying mathematical giftedness. As Miller (1990) pointed out, 'IQ test results often yield valuable information and may provide clues to the existence of mathematical talent.'

In many gifted programs in the USA, both achievement tests and IQ tests are considered valid criteria to identify mathematical giftedness. For example, in Indiana of the USA, it is stated that a student should be M-HA (of mathematically high ability) if the child is designated 'High Ability - General Intellectual' (e.g. has scored two standard deviations above the mean, minus the standard error of measurement, on an individual standardized intelligence test or a standardized group intelligence test.). Additionally, any other student should have this designation of M-HA if the child, in the past 24 months, performed at or above the 93 percentile on the Math Reasoning or Problem Solving or Math Composite portion of an individual or group standardized achievement test (Indiana Department of Education, 2004).

The combination of IQ tests and achievement tests is the usual method of identifying mathematically gifted students who possess good potentials to do well in mathematics yet cannot perform satisfactorily in traditional examinations or in the school context. For example, Lau and Chan (2001) also used intelligence test (RAVEN's SPM) and a mathematics achievement test (the school examination) together to identify gifted underachievers in mathematics.

According to the Cambridge Advanced Learner's Dictionary (Cambridge University Press, 2003), attitude means "a feeling or opinion about something or someone, or a way of behaving that is caused by this". It could thus be infered that attitude towards mathematics can be defined as "a feeling or opinion about mathematics or learning of mathematics, or a way of behaving that is caused by this." The Prentice Hall Online Glossary (2006) defines attitudes as "the positive, neutral, or negative feelings a person has about the economy, politics, goods, services, institutions, and so on." That is it could be infered that attitude towards mathematics means "the positive, neutral, or negative feelings a person has about mathematics or the learning of mathematics." Both definitions draw attention to how "attitude" is concerned with "feelings".

Renzulli's (1998) three-ring conception of giftedness defined giftedness as the interaction of above average ability, creativity and task commitment. This highlights the importance of non-intellective elements, such as interest and persistence, in the development of giftedness. Renzulli defines the following "taxonomy" of behavioral manifestations of task commitment.

"The capacity for high levels of interest, enthusiasm, fascination, and involvement in a particular problem, area of study, or form of human expression. - The capacity for perseverance, endurance, determination, hard work, and dedicated practice. Self-confidence, a strong ego and a belief in one's ability to carry out important work, freedom from inferiority feelings, drive to achieve. - The ability to identify significant problems within specialized areas; the ability to tune in to major channels of communication and new developments within given fields. Setting high standards for one's work; maintaining an openness to self and external criticism; developing an aesthetic sense of taste, quality, and excellence about one's own work and the work of others”. (p. 18).

From the above, we see that task commitment is closely related to attitude. Gifted people hold more positive attitudes (or feelings) towards a challenging task. They tend to be more interested in the task, have more self-confidence in their ability to perform the task well, and are more willing to spend time on the task than "non-gifted" people. 
There are many studies that support Renzulli's view about the importance of task commitment and attitudes. For example, McCoach and Siegle (2001) compared 122 gifted achievers with 56 gifted underachievers in 28 different high schools. They found that gifted underachievers differed from achievers on four factors: attitudes toward teachers, attitudes toward school, goal valuation, and motivation/self-regulation. This supports the importance of attitudes in the development and expression of giftedness.

Fennema and Sherman (1976) constructed an attitude scale for mathematics, which has become "one of the most popular instruments used in research over the last three decades” (Tapia \& Marsh II, 2004). The scale consists of nine subscales:

(1) Attitude Toward Success in Mathematics Scale,

(2) Mathematics as a Male Domain Scale,

(3) Mother Scale,

(4) Father Scale,

(5) Teacher Scale,

(6) Confidence in Learning Mathematics Scale,

(7) Mathematics Anxiety Scale,

(8) Effectance Motivation Scale in Mathematics, and

(9) Mathematics Usefulness Scale.

The Fennema-Sherman scale assesses many aspects of a student's feelings towards mathematics and the learning of mathematics. However, the original Fennema-Sherman scales were too long, and time-consuming, to be used in the present study. In addition, the wording of items on the original scales was, in many cases, unsuitable --- linguistically and culturally --- for Nigerian primary school children. So instead of directly using the original scale, the present author modified the scales that Fennema \& Sherman had developed, and validated the scales again.

Under the current policy of inclusive education, schools are encouraged to design and implement school-based gifted curriculum to cater for the special needs of gifted schoolchildren. This is important to gifted pupils in developing their potentials, and also important to society as a whole since gifted pupils may make enormous contribution to society if they are suitably supported.

As regard to the identification of mathematically gifted pupils, the problem is very controversial. In Nigeria, National Examinations Council (NECO) is saddle with the responsibility of conducting a yearly examination which is used in selecting gifted student for gifted programs in the gifted school that is located at Suleja Niger State. However, Cai (1995) found that pupils good at solving routine mathematics problems are not necessarily good at solving non-routine mathematics problems. Empirical evidence also shows the existence of gifted underachievers who are high in cognitive ability but fail to attain the scholastic level as predicted by their abilities (Colangelo, Kerr, Christensen, \& Maxey, 1993; Lau \& Chan, 2001; Vlahovic-stetic, Vidovic, \& Arambasic, 1999). Therefore, one cannot rely solely on school examinations or the NECO yearly examination in identifying mathematically gifted school children because most of the examinations consist mainly of routine problems. If we regard mathematically gifted pupils as those excelling in mathematics problem solving, especially of non-routine problems that ask for higher order thinking and creativity, then it should be more valid to use non-routine problems (Krutetskii, 1976).

So for school-based gifted education to be successful, there is a need for teachers to understand more of the non-routine methods of assessment and the real abilities of mathematically gifted children for more effective identification and curriculum design strategies. Besides cognitive abilities, teachers should also understand more the attitudes of their pupils, such as interest and motivation, when selecting pupils for gifted programs. This explains why the present author did the study.

The main objective was to investigate the psychology of mathematically gifted school children, affective aspects. The findings of which should be useful to teachers when they identify gifted pupils and develop school-based gifted programs. The specific objective of the study are as follow:

1. To design and validate an attitude scale for assessing the attitudes students towards mathematics;

2. To use the validated instruments to measure pupils' attitude towards mathematics in some representative samples of mathematically gifted and non-gifted students as identified by the researcher. 


\section{Research Hypotheses}

1. The differences between the mean score of the gifted group and that of the non-gifted group in overall attitude towards mathematics would not be significantly greater than zero.

2. The differences between the mean scores of the gifted group and those of the non-gifted group in each of the four componential attitudes would not be significantlydifferent.

\section{Method}

\subsection{Population and sample}

The population for the study was made up Junior Secondary Three students (JS3) in the Osun East Senatorial constituency. The study sample was made up of 300 (125 boys and 175 girls) JS 3 students from ten randomly selected Junior Secondary Schools (JSS) from the Senatorial constituency. 30 students were randomly selected from each of the 10 JSSs. Sixty-eight of them (32 boys and 36 girls) were identified to be mathematically gifted; One hundred and ninety-five (75 boys and 120 girls) and thirty-seven (18 boys and 19 girls) were identified to be average and gifted underachievers respectively.

\subsection{Procedure for classification of students}

In the study two instruments RAVEN's Standard Progressive Matrices (SPM) and Mathematics Achievement Test (MAT) were administered on the selected 300 JS3 students. Those students who scored high on both RAVEN's SPM test and MAT test were defined to be mathematically gifted. Sixty-eight students from this group participated in the present study, and they are called the mathematically gifted group. The study further defined gifted underachievers as those who scored high on RAVEN's SPM but low in MAT. This group was made of 195 students and they are called the underachievers' group in this study.

The study defined average pupils as those who scored average in both RAVEN's SPM and MAT. This group behaved moderately in both general intelligence and mathematics achievement. This group in this study was made up of thirty-seven students and hereafter they are referred to as the average group.

\subsection{Instruments}

Three instruments were used in carrying out this study. The first instrument was an adapted RAVEN's Standard Progressive Matrices (SPM). It was a non-verbal assessment of general intelligence in people, applicable to people aged 5 years and over. It consisted of 60 multiple-choice items designed to measure a person's ability to form perceptual relations and to reason by analogy independent of language and schooling. It was a group-administered intelligence test, of about 40 minutes duration, that has been widely used by researchers all over the world.

The second instrument was a self constructed Mathematics Achievement Test (MAT) that covers the Junior Secondary School Mathematics Syllabus. It was made up 50 multiple choice objective test items. The initial number of items constructed by the researcher was 80 items. This was trial tested using 50 students of a junior secondary school III that is based in the Osun Central Senatorial Constituency. The psychometric properties of the 80 items were determined and 50 items whose difficulty index and discrimination index falls between 0.45 and 0.85 and 0.40 and above respectively were selected. The MAT mainly tested the students' mastery of the Junior Secondary School mathematics syllabus. The selected 50 items made up the final 50-minutes test.

The third instrument was an adapted Fennema and Sherman (1976) Attitude Scale (AS). Fennema and Sherman (1976) constructed an attitude scale towards mathematics, which has become 'one of the most popular instruments used in research over the last three decades' (Tapia \& Marsh II, 2004). The scale consists of nine subscales: Attitude Toward Success in Mathematics Scale, Mathematics as a Male Domain Scale, Mother Scale, Father Scale, Teacher Scale, Confidence in Learning Mathematics Scale, Mathematics Anxiety Scale, Effectance Motivation Scale in Mathematics, and Mathematics Usefulness Scale. Each of these subscales consists of 12 items. Six of them measure a positive attitude and six measure a negative attitude.

The original Fennema-Sherman scale might be too long and too time-consuming for JS 3 students. It is also observed that the wordings might not be appropriate for the Nigeria (Osun State) context due to cultural differences. So instead of directly using the foreign scale, the present author adopted the use of the factors Fennema and Sherman had proposed.

In this study the researcher made use of only four of the nine sub-scales that is believed to be the most relevant to the learning of JS 3 students in Osun State. They are: confidence in learning mathematics, anxiety, motivation, and perceived usefulness of mathematics. In this study the factor of 'anxiety' was expanded to 'negative feelings towards mathematics' since other negative feelings such as hatred and indifference should also affect attitude towards 
mathematics. The factor of “motivation" was also redefined as "interest and commitment” since Renzulli's (1978) three-ring model of giftedness defined giftedness as the interaction of above average ability, creativity and task commitment. By 'task commitment' Renzulli meant 'interest' as well as the usual sense of 'commitment' of willing to give time and energy to do something. Changing the factor 'motivation' to 'interest and commitment' could allow Renzulli's three-ring model to be tested in the present study.

In this study the selected factors of attitude towards mathematics were defined as follows:

Factor 1: 'Confidence in mathematics' means the student is certain of his/her abilities in mathematics and has trust in getting good mathematics results.

Factor 2: 'Perceived value of mathematics' means the student considers mathematics to be important and useful to himself/herself.

Factor 3: 'Interest and commitment in mathematics' means the student likes to give his/her attention to mathematics and to learn more about mathematics; he/she is willing to give his/her time and energy to mathematics, he/she has a firm decision to finish a mathematics problem, course, study, etc.

Factor 4: 'Negative feelings towards mathematics' means the student has negative feelings towards mathematics, such as being anxious, not caring, disgust, despise, etc.

Using the definition giving to the four selected factors in this study, a 17-items questionnaire that is relevant to Osun State JSS context was designed. Students were instructed to indicate their degree of agreement to each of the 17- item statements. The options were: Strongly Disagree $=1$, Disagree $=2$, Agree $=3$, Strongly Agree $=4$

\subsection{Piloting the Instrument in a Local School}

The constructed 17-items questionnaire was piloted with 50 students of a junior secondary school III that is based in the Osun Central Senatorial constituency. There were 27 girls and 23 boys. The questionnaire was written in the English language. The wordings were simple enough for JS 3students to understand correctly. Pupils were also allowed to ask questions in case they had problems in filling in the questionnaire.

Missing values were handled by list-wise deletion, that is, if the pupil did not respond to one or more of the 17 items, the whole case was deleted. There were five such cases, so the number of valid cases was reduced to 45.

Items 15, 16 and 17 were about negative feelings towards mathematics, and so were reversely coded in the data analysis. The minimum, maximum, mean and standard deviation of the item scores are as follows (Table 1).

$<$ Table 1 about here $>$

As used in the study, with the four point Likert scale (1 for strongly disagree, 2 for disagree, 3 for agree, and 4 for strongly agree), items with means below 2.5 were considered to be on the 'disagree' side, while items with means greater than 2.5 were considered to be on the 'agree' side and vice versa for items structured in the negative. So Q3 (I am very gifted in mathematics.), Q9 (I like reading math and related books.) and Q13(I am always ready to spend extra time to think about a math problem until I have solved it.), Q15 (I have fear for math tests.), Q16 (Math is of no use.) and Q17 (I don't want to do any math related jobs in the future.). were on the 'disagree' side, while the other items were on the 'agree' side. Hence, pupils tended to disagree with Q3, Q9 and Q13, Q15, Q16 andQ17, while they agree with the other items. Q3 (I am very gifted in mathematics.) was the most disagreed item, with mean 2.20. Q4 (Math is very important in daily life.) was the most agreed item, with mean 3.45.

\subsection{Reliability of the Attitude Scale}

To determine the reliability of the AS Statistical Package for Social Sciences (SPSS) was used and thus the item-total statistics for the pilot study were found to be as follows:

\section{$<$ Tables 2 \& 3 about here>}

As shown in Table, all corrected item-total correlations were greater than 0.4, showing that all the items were "good" items in the sense that if a pupil scored high in a certain item, then he/she was also likely to score high in the total score of the questionnaire.

The reliability estimate using the Cronbach's Coefficient Alpha yielded an internal consistency value of 0.94, showing that the reliability of the attitude scale was high.

3.6 Validity of the Attitude Scale 
The 17 items were supposed to measure the attitude towards mathematics of the junior secondary school students. Within this construct of attitude towards mathematics, four factors were hypothesized, namely 'Confidence', 'Value', 'Interest \& Commitment' and 'Negative Feelings'. Items were categorized as follows:

This four-factor structure of attitude was put to test by confirmatory factor analysis using the computer program LISREL8 (Joreskog \& Sorbom, 1993). Results were show in Table 4.

$<$ Table 4 about here $>$

As it was contained in the original design of the questionnaire each of the items were related to one factor. The result relationship as revealed in the Table4 shows that all factor loadings were larger than 0.6. (The absolute values of factor loadings always lie between 0 and 1 . The closer the absolute value of a factor loading to 1 , the more relevance the item is to the factor, and hence the better the item will be.)

The goodness of fit measures, such as GFI, AGFI, NFI and CFI with the values (1.00, 0.99, 0.97 and1.00) respectively are greater than the cut off value of 0.95 indicating that the four-factor model fits the data well. Therefore the overall goodness of fit can be accepted. From Table5 it could be observed the four factors are moderately correlated, with correlation coefficients from 0.59 to 0.81 . Hence the four-factor model of the attitude-scale towards mathematics was confirmed by the confirmatory factor analysis, thus establishing the construct validity of the instrument.

$<$ Tables 5 \& 6 about here>

\section{Results and Findings from the Descriptive Statistics}

Students' attitude as related to a factor is determined through partial sum of the items that made up the factor. (i.e. 'Confidence'= Sum of Items 1 to 3; 'Value'= Sum of Items 4 to 6; 'Interest' = Sum of Items 11 to 18 ; 'Negative Feelings'= Sum of Items 19 to 21.) Table 12.1 above also shows the statistics of the four factors as assessed by the partial sums. The total score of the attitude scale was the sum of scores of all the 17 items (Chart 12.2). The mean score was 60.29, and the standard deviation was 11.45 . Table 7 presents the correlations among the four factors and the total score all correlations are significant at 0.01 level.

\section{$<$ Table 7 about here $>$}

Considering the 68 identified mathematically gifted students the following statistics as presented on Table 8 was obtained. From the Table 8 it could be observed that all the means of the gifted group $(n=68)$ are greater than the whole group mean $(n=300)$. The total minimum score of 46 and maximum score 67 is an indication that all the students identified in this study as being mathematically gifted tends to be more positive in all the attitudes concerned when compared with the whole sampled group. This was further strengthened by the group mean attitudinal value of 60. 29 .

\section{$<$ Table 8 about here $>$}

From Table 9 it could be observed that all the means in the underachieving group $(n=37)$ are smaller than those in the whole group $(\mathrm{n}=300)$. This indicates that the underachievers tend to be more negative in all the attitudes concerned as compared with the whole sampled group.

$<$ Table 9 about here>

The average group represented the students with average abilities in the sampled population. It could be observed in the Table 10 that except the mean of question 17 all other mean are are smaller than those in the whole group. But with the total mean value of 51.44 the group tends not to have negative feeling towards all the attitudes concerned when compared with the whole sample. ANOVA with Scheffe multiple comparisons, was then used to test the differences among the three ability groups, [the mathematically gifted (MG), the underachieving (U), and the average (A)]. The results were presented in Table 11.

\section{$<$ Tables 10 \& 11 about here>}

It could be observed in the Table11, that the mathematically gifted group has significantly better attitudes, at 0.05 level, than the average and underachiever groups in all the four factors of attitudes towards mathematics that was considered in the study and also in the total score. Thus hypotheses 1 and 2 were rejected. The Table also presented the fact that the underachieving group has better significant attitude in 'confidence', but poorer attitudes in 'value', 'interest', 'negative feeling' and the total score as compared with the average group, and all these differences are significant at 0.05 level. It could therefore be concluded that the underachievers have the least value, interest and commitment in mathematics as well as having the greatest negative feeling towards mathematics 


\section{Discussion}

It was found from the study that the mathematically gifted group has significantly better attitudes than the average group in all the four factors of attitudes towards mathematics ('Confidence', 'Value', 'Interest' and 'Negative Feeling'), and also in the total score of the attitude scale. This suggests that the mathematically gifted student: (i) is certain of his/her abilities in mathematics and has trust in getting good mathematics results; (2) considers mathematics to be useful to himself/herself; (3) likes to give his/her attention to mathematics and to learn more about mathematics; is willing to give his/her time and energy to mathematics, has a firm decision to finish a mathematics problem, course, study, etc.; and (4) has less negative feelings towards mathematics, such as anxiety, indifference, disgust and despise. All these help the student to develop his/her giftedness in mathematics. It was also found out that the mathematically gifted pupils had greater interest and commitment. Regarding perceived value of mathematics, the mathematically gifted pupils tended to see mathematics as a useful subject with many applications, such as career applications, daily life applications, mathematically specific applications, applications in all areas of life, and applications as a tool for learning other subjects. Interestingly, it was also discovered that the mathematically gifted pupils preferred more challenging mathematics problems. They might find the daily mathematics problems too easy or too routine. They preferred to have more challenging problems in class, posed by teachers or peers.

Are these characteristics inborn and predetermined? Or can they be nurtured? This nature-nurture controversy has aroused much debate among academics for many decades. While many people maintain that giftedness is very largely predetermined, the present author believes that some of the abilities possessed by gifted students can also be nurtured in other people, and there is still some room for teachers and parents to do to help. According to the present study, mathematically gifted students do have some very effective strategies in dealing with mathematical problems. Many of these strategies can actually be learned by other students. This can enhance their ability to solve mathematical problems. Note that many such strategies can be taught and learnt. For example, teachers can teach students to spend more time to decode a problem rather than hurrying to give an answer, and make this a habit of the mind; teachers can teach their students to use educated or systematic guesses, and to check their answers and conclusions constantly, and so forth.

\section{References}

Benbow, C. (1991). Mathematically talented children: Can acceleration meet their educational needs? In N. Colangelo \& G. Davis (Eds.),Handbook of Gifted Education (pp. 154-165). Boston: Allyn \& Bacon.

Cai, J. (1995). A cognitive analysis of US and Chinese pupils' mathematical performance on tasks involving computation, simple problem solving, and complex problem solving. Journal for Research in Mathematics Education Monograph Series. Reston, VA: National Council of Teachers of Mathematics.

Cambridge University Press (2003). Cambridge advanced learner's dictionary. Cambridge: Cambridge University Press.

Colangelo, N., Kerr, B., Christensen, P. \& Maxey, J. (1993). A comparison of gifted under-achievers and gifted high achievers, Gifted Child Quarterly, 37(1), 155-160. doi:10.1177/001698629303700404, http://dx.doi.org/10.1177/001698629303700404

Davis, G.A., \& Rimm, S.B. (1998). Education of the gifted and talented. MA: Allyn \& Bacon.

Fennema, E., \& Sherman, J. A. (1976). Fennema-Sherman Mathematics Attitude Scales. Catalog of selected documents in psychology, 6, 31 (Ms. No. 1225).

Indiana Department of Education Division of Exceptional Learners Gifted and Talented (2004). Indiana standards for high ability education field study edition---August 5, 2004. Retrieved January 24, 2007 from http://www.ecesc.k12.in.us/IndianaStandardsforHighAbilityEducation3.pdf

Joreskog, K.G., \& Sorbom, D. (1993). LISREL 8: Structural equation modeling with the SIMPLIS command language. Chicago, Ill.: Scientific Software International.

Krutetskii, V. A. (1976). The psychology of mathematical abilities in schoolchildren. Chicago: University of Chicago Press.

Lau, K.L. \& Chan, D.W. (2001). Identification of underachievers in Hong Kong: do different methods select different underachievers? Educational Studies, 27(2), 187-200. doi:10.1080/03055690120050419, http://dx.doi.org/10.1080/03055690120050419

Marland, S. P., Jr. (1972). Education of the gifted and talented, Volume 1. Report to the Congress of the United States by the U. S. Commissioner of Education. Washington, DC: U.S. Government Printing Office. 
McCoach, D. B., \& Siegle, D. (2001). Factors that differentiate gifted achievers from gifted underachievers. Paper presented at the annual conference of the American Educational Research Association, Seattle.

Miller, R. C. (1990). Discovering mathematical talent. ERIC Clearinghouse on Disabilities and Gifted Education (ERIC EC). ERIC EC Digest \#E482.

Prentice-Hall (2006). Online Glossary http://www.prenhall.com/rm_student/html/glossary/a_gloss.html

Renzulli, J. S. (1978). What makes giftedness? Reexamining a definition. Phi Delta Kappan, 60, 180-184, 261.

Renzulli, J. S. (1986). The three-ring conception of giftedness: A developmental model for creative productivity. In R. J. Sternberg \& J. E. Davidson (Eds.), Conceptions of Giftedness (pp. 53-92). Cambridge, MA: Cambridge University Press.

Renzulli, J. S. (1998). The three-ring conception of giftedness. In Baum, S. M., Reis, S. M., \& Maxfield, L. R. (Eds.). Nurturing the gifts and talents of primary grade students. Mansfield Center, CT: Creative Learning Press.

Ridge, H.L., \& Renzulli, J.S. (1981). Teaching mathematics to the talented and gifted. In V.J. Glennon (Ed.), The mathematical education of exceptional children and youth: An interdisciplinary approach (pp. 191-266). Reston: National Council of Teachers of Mathematics.

Stanley, J., Keating, D. \& Fox, L. (Eds.) (1974). Mathematical talent. Baltimore: Johns Hopkins Press.

Tapia, M. \& Marsh II, G. E. (2004). An instrument to measure mathematics attitudes. Academic Exchange Quarterly. 2004, Vol 8 (2).

Vlahovic-stetic, V., Vidovic, V. \& Arambasic, L. (1999). Motivational characteristics in mathematical achievement: A study of gifted high-achieving, gifted underachieving and non-gifted pupils, High Ability Studies, 10(1), 37-49. doi:10.1080/1359813990100104

Table 1. Item statistics of the piloted attitude scale towards mathematics

\begin{tabular}{|l|c|c|c|c|c|c|c|c|c|}
\hline & Min. & Max. & Mean & St. Deviation & & Min. & Max. & Mean & St. Deviation \\
\hline Q1 & 1.00 & 4.00 & 2.57 & 0.83 & Q10 & 1.00 & 4.00 & 2.73 & 0.89 \\
\hline Q2 & 1.00 & 4.00 & 2.73 & 0.86 & Q11 & 1.00 & 4.00 & 2.88 & 0.86 \\
\hline Q3 & 1.00 & 4.00 & 2.20 & 0.85 & Q12 & 1.00 & 4.00 & 2.57 & 0.87 \\
\hline Q4 & 1.00 & 4.00 & 3.45 & 0.63 & Q13 & 1.00 & 4.00 & 2.52 & 0.83 \\
\hline Q5 & 1.00 & 4.00 & 3.22 & 0.70 & Q14 & 1.00 & 4.00 & 2.63 & 0.90 \\
\hline Q6 & 1.00 & 4.00 & 3.19 & 0.73 & Q15 & 1.00 & 4.00 & 2.73 & 0.99 \\
\hline Q7 & 1.00 & 4.00 & 2.90 & 0.75 & Q16 & 1.00 & 4.00 & 3.59 & 0.76 \\
\hline Q8 & 1.00 & 4.00 & 2.56 & 0.96 & Q17 & 1.00 & 4.00 & 3.04 & 0.90 \\
\hline Q9 & 1.00 & 4.00 & 2.45 & 0.83 & & & & & \\
\hline
\end{tabular}

Valid $\mathrm{n}=45$

Table 2. Item-total statistics of the pilot study

\begin{tabular}{|c|c|c|c|c|c|}
\hline Items & $\begin{array}{c}\text { Corr. item-total } \\
\text { Correlation }\end{array}$ & Alpha if item Deleted & Items & $\begin{array}{c}\text { Corr. item-total } \\
\text { Correlation }\end{array}$ & Alpha if item Deleted \\
\hline Q1 & 0.71 & 0.93 & Q10 & 0.88 & 0.95 \\
\hline Q2 & 0.77 & 0.93 & Q11 & 0.77 & 0.93 \\
\hline Q3 & 0.64 & 0.95 & Q12 & 0.65 & 0.95 \\
\hline Q4 & 0.57 & 0.95 & Q13 & 0.67 & 0.93 \\
\hline Q5 & 0.69 & 0.93 & Q14 & 0.76 & 0.93 \\
\hline Q6 & 0.74 & 0.93 & Q15 & 0.63 & 0.95 \\
\hline
\end{tabular}




\begin{tabular}{|c|l|l|l|l|l|}
\hline Q7 & 0.79 & 0.93 & Q16 & 0.55 & 0.95 \\
\hline Q8 & 0.82 & 0.93 & Q17 & 0.52 & 0.95 \\
\hline Q9 & 0.69 & 0.93 & & & \\
\hline
\end{tabular}

Alpha $=0.93$

Table 3. The four factors that were considered

\begin{tabular}{|l|l|}
\hline Factors of Attitude towards mathematics & Items \\
\hline 'Confidence' & Items 1-3 \\
\hline 'Value' & Items 4-6 \\
\hline 'Interest \& Commitment' & Items 7-14 \\
\hline 'Negative Feelings' & Items 15-17 \\
\hline
\end{tabular}

Table 4. Factor loadings of the 17 items on the four factors

\begin{tabular}{|c|c|c|c|c|c|c|c|c|c|}
\hline Items & Confidence & Value & Int.\&Commit. & $\begin{array}{c}\text { Neg. } \\
\text { Feeling }\end{array}$ & Items & Confidence & Value & Int.\&Commit. & $\begin{array}{c}\text { Neg. } \\
\text { Feeling }\end{array}$ \\
\hline Q1 & 0.86 & & & & Q10 & & & 0.90 & \\
\hline Q2 & 0.99 & & & & Q11 & & & 0.85 & \\
\hline Q3 & 0.80 & & & & Q12 & & & 0.66 & \\
\hline Q4 & & 0.70 & & & Q13 & & & 0.72 & \\
\hline Q5 & & 0.88 & & & Q14 & & & 0.84 & \\
\hline Q6 & & 0.78 & & & Q15 & & & & 0.89 \\
\hline Q7 & & & & & Q16 & & & & 0.70 \\
\hline Q8 & & & 0.86 & & Q17 & & & & 0.66 \\
\hline Q9 & & & 0.78 & & & & & & \\
\hline
\end{tabular}

Blank spaces in the table refer to negligible factor loadings with absolute values less than 0.30 .

Table 5. Factor correlation matrix

\begin{tabular}{|l|c|c|c|c|}
\hline Factor & Confidence & Value & Int.\&Commit. & Neg Feeling \\
\hline Confidence & 1.00 & 0.65 & 0.81 & 0.67 \\
\hline Value & 0.65 & 1.00 & 0.75 & 0.59 \\
\hline Int.\&Commit. & 0.81 & 0.75 & 1.00 & 0.73 \\
\hline Neg Feeling & 0.67 & 0.59 & 0.73 & 1.00 \\
\hline
\end{tabular}

Table 6. Descriptive statistics of the 17 items and the four factors of attitude towards mathematics in the main study

\begin{tabular}{|c|c|c|c|c|c|c|c|c|c|}
\hline & Min. & Max. & Mean & SD & & Min. & Max. & Mean & SD \\
\hline Q1 & 1.00 & 4.00 & 3.38 & 0.59 & Q10 & 1.00 & 4.00 & 3.47 & 0.66 \\
\hline Q2 & 1.00 & 4.00 & 3.28 & 0.65 & Q11 & 1.00 & 4.00 & 3.51 & 0.72 \\
\hline Q3 & 1.00 & 4.00 & 2.74 & 0.63 & Q12 & 1.00 & 4.00 & 3.34 & 0.69 \\
\hline Q4 & 1.00 & 4.00 & 3.75 & 0.66 & Q13 & 1.00 & 4.00 & 3.33 & 0.67 \\
\hline Q5 & 1.00 & 4.00 & 3.78 & 0.65 & Q14 & 1.00 & 4.00 & 3.50 & 0.47 \\
\hline
\end{tabular}




\begin{tabular}{|c|c|c|c|c|c|c|c|c|c|}
\hline Q6 & 1.00 & 4.00 & 3.82 & 0.57 & Q15 & 1.00 & 4.00 & 3.40 & 0.89 \\
\hline Q7 & 1.00 & 4.00 & 3.44 & 0.73 & Q16 & 1.00 & 4.00 & 3.87 & 0.59 \\
\hline Q8 & 1.00 & 4.00 & 3.40 & 0.71 & Q17 & 1.00 & 4.00 & 3.45 & 0.83 \\
\hline Q9 & 1.00 & 4.00 & 3.00 & 0.74 & Total Score & 31.0 & 67.0 & 56.7 & 11.45 \\
\hline
\end{tabular}

Table7. Correlations among factors and the total score in the attitude scale

\begin{tabular}{|l|c|c|c|c|c|}
\hline & 'Confidence' & 'Value' & 'Interest' & 'Neg. Feeling' & Total Score \\
\hline 'Confidence' & 1.00 & 0.33 & 0.57 & 0.53 & 0.75 \\
\hline 'Value' & 0.33 & 1.00 & 0.59 & 0.41 & 0.72 \\
\hline 'Interest' & 0.57 & 0.59 & 1.00 & 0.63 & 0.97 \\
\hline 'Neg. Feeling' & 0.53 & 0.41 & 0.63 & 1.00 & 0.79 \\
\hline Total Score & 0.75 & 0.72 & 0.97 & 0.79 & 1.00 \\
\hline
\end{tabular}

Table 8. Descriptive statistics of the 17 items and the our factors of attitude towards mathematics in the main study for the 68 gifted students

\begin{tabular}{|c|c|c|c|c|c|c|c|c|c|}
\hline & Min. & Max. & Mean & SD & & Min. & Max. & Mean & SD \\
\hline Q1 & 1.00 & 4.00 & 3.46 & 0.55 & Q10 & 2.00 & 4.00 & 3.58 & 0.58 \\
\hline Q2 & 1.00 & 4.00 & 3.36 & 0.64 & Q11 & 1.00 & 4.00 & 3.55 & 0.51 \\
\hline Q3 & 1.00 & 3.00 & 2.90 & 0.52 & Q12 & 2.00 & 4.00 & 3.36 & 0.62 \\
\hline Q4 & 2.00 & 4.00 & 3.92 & 0.44 & Q13 & 2.00 & 4.00 & 3.40 & 0.63 \\
\hline Q5 & 2.00 & 4.00 & 3.95 & 0.42 & Q14 & 1.00 & 4.00 & 3.54 & 0.55 \\
\hline Q6 & 2.00 & 4.00 & 3.96 & 0.45 & Q15 & 1.00 & 4.00 & 3.58 & 0.76 \\
\hline Q7 & 2.00 & 4.00 & 3.53 & 0.57 & Q16 & 2.00 & 4.00 & 4.12 & 0.40 \\
\hline Q8 & 2.00 & 4.00 & 3.43 & 0.58 & Q17 & 2.00 & 4.00 & 3.62 & 0.55 \\
\hline Q9 & 2.00 & 4.00 & 3.03 & 0.72 & Total Score & 46.0 & 67.0 & 60.29 & 9.49 \\
\hline
\end{tabular}

Table 9. Descriptive statistics of the 17 items and the four factors of attitude towards mathematics in the main study for the 37 underachiever students

\begin{tabular}{|c|c|c|c|c|c|c|c|c|c|}
\hline & Min. & Max. & Mean & SD & & Min. & Max. & Mean & SD \\
\hline Q1 & 1.00 & 3.00 & 2.86 & 0.63 & Q10 & 1.00 & 3.00 & 2.65 & 0.73 \\
\hline Q2 & 1.00 & 3.00 & 2.76 & 0.70 & Q11 & 1.00 & 4.00 & 2.50 & 1.02 \\
\hline Q3 & 1.00 & 4.00 & 2.41 & 0.91 & Q12 & 2.00 & 3.00 & 2.62 & 0.51 \\
\hline Q4 & 1.00 & 4.00 & 3.65 & 0.53 & Q13 & 1.00 & 4.00 & 2.94 & 1.02 \\
\hline Q5 & 2.00 & 3.00 & 3.41 & 0.76 & Q14 & 1.00 & 3.00 & 2.84 & 1.07 \\
\hline Q6 & 1.00 & 4.00 & 3.31 & 1.03 & Q15 & 1.00 & 4.00 & 2.94 & 0.93 \\
\hline Q7 & 1.00 & 3.00 & 2.75 & 0.47 & Q16 & 1.00 & 4.00 & 3.61 & 0.82 \\
\hline Q8 & 1.00 & 4.00 & 2.87 & 0.96 & Q17 & 1.00 & 3.00 & 2.77 & 1.05 \\
\hline Q9 & 1.00 & 4.00 & 2.19 & 0.86 & Total Score & 25.00 & 51.0 & 49.08 & 9.14 \\
\hline
\end{tabular}


Table 10. Descriptive statistics of the 17 items and the four factors of attitude towards mathematics in the main study for the 195 average students

\begin{tabular}{|c|c|c|c|c|c|c|c|c|c|}
\hline & Min. & Max. & Mean & SD & & Min. & Max. & Mean & SD \\
\hline Q1 & 1.00 & 4.00 & 2.98 & 0.60 & Q10 & 1.00 & 4.00 & 3.03 & 0.82 \\
\hline Q2 & 1.00 & 4.00 & 2.81 & 0.64 & Q11 & 1.00 & 4.00 & 2.89 & 0.77 \\
\hline Q3 & 1.00 & 4.00 & 2.54 & 0.77 & Q12 & 1.00 & 4.00 & 2.63 & 0.75 \\
\hline Q4 & 1.00 & 4.00 & 3.65 & 0.63 & Q13 & 1.00 & 4.00 & 2.72 & 0.74 \\
\hline Q5 & 2.00 & 4.00 & 3.49 & 0.60 & Q14 & 1.00 & 4.00 & 2.88 & 0.74 \\
\hline Q6 & 2.00 & 4.00 & 3.39 & 0.59 & Q15 & 1.00 & 4.00 & 3.00 & 0.80 \\
\hline Q7 & 1.00 & 4.00 & 2.91 & 0.80 & Q16 & 2.00 & 4.00 & 3.61 & 0.53 \\
\hline Q8 & 1.00 & 4.00 & 2.81 & 0.71 & Q17 & 1.00 & 4.00 & $3.79 *$ & 0.94 \\
\hline Q9 & 1.00 & 4.00 & 2.31 & 0.82 & Total Score & 35.0 & 59.0 & 51.44 & 12.25 \\
\hline
\end{tabular}

Table 11. One way ANOVA with Scheffe multiple comparisons among the three groups

\begin{tabular}{|l|c|c|c|c|c|c|}
\hline \multirow{2}{*}{ Factors } & \multicolumn{3}{|c|}{ Group Means } & \multicolumn{2}{c|}{ Differences bet. Groups } \\
\cline { 2 - 7 } & MG & U & A & MG\&U & MG\&A & U\&A \\
\hline 'Confidence' & 10.01 & 7.12 & 5.79 & $2.18^{*}$ & $1.97^{*}$ & $0.98^{*}$ \\
\hline 'Value' & 11.05 & 9.45 & 9.87 & $2.01^{*}$ & $1.75^{*}$ & 0.45 \\
\hline 'Interest' & 28.94 & 17.41 & 20.33 & $4.43^{*}$ & $3.15^{*}$ & $1.79^{*}$ \\
\hline 'Neg. Feeling' & 11.05 & 8.43 & 9.15 & $3.57^{*}$ & $1.89^{*}$ & $1.87^{*}$ \\
\hline Total score & 60.29 & 49.08 & 51.44 & $10.25^{*}$ & $8.79^{*}$ & $4.23^{*}$ \\
\hline
\end{tabular}

